\title{
The Tragedy of the Park: an Agent-based Model of Endogenous and Exogenous Institutions for Forest Management
}

\author{
Elena Vallino $^{1}$
}

\begin{abstract}
Many scholars of common-pool resources have found that institutions might solve the tragedy of the commons. I address a particular situation of natural resource management: that of a protected area. In this situation, interests differ. Local rural inhabitants care about the quality of their environment but also need to exploit the resources for livelihood reasons. An external entity such as the State, a donor, an NGO, or some combination thereof decides that there is a need for nature conservation in that area. Because of some evidence of failure for a strictly top-down conservationist approach, the external entity decides to apply the concept of participatory conservation: the local inhabitants become stakeholders in the management of the area and become collectively responsible for conservation, with rights to exploit the resources up to some degree. I argue that project designers try to find a solution to nature conservation through the creation of a situation of a commons: creating a community that has rights and duties toward a particular natural area that is endowed with some resources. Many scholars rely mostly on institutions that are endogenously created within the users' community to avoid the tragedy of the commons. However, what happens if institutions are imposed? In participatory conservation initiatives, the community has collective rights over the resources, and in this sense, the issue of endogenous rules for the commons management is relevant. However, the level to which the community should exploit the resource is usually imposed by the external project designers. Using agent-based simulations, I develop a theoretical model to look at the consequences of an imposed institution on the state of a forest and on the users' profit, taking into account the possibilities of violating the imposed rules and facing enforcement. I compare the consequences of this imposed institution with those deriving from an endogenously created institution. I also analyze the interaction between the different kinds of institutions and the individual perceptions of each agent. Many results of the model confirm the quantitative and qualitative findings of the literature: the presence of institutions and enforcement improve the management of the resource with respect to an open-access situation, with different degree of success depending on the kind of institution in place. The two main counterintuitive findings are the following. First, an exogenous institution imposed by external agents may crowd out agents' intrinsic environmental motivations. Second, when an imposed exogenous institution is in place, the most effective rule is one allowing a sufficient degree of access to resources for the agents, provided that adequate rule enforcement is implemented.
\end{abstract}

Key Words: agent-based models; commons; institutions; participatory conservation; protected areas

\section{INTRODUCTION}

Scholars of the commons widely agree on the possibility that institutions endogenously created by a community of people to manage a common-pool resource may be able, under certain conditions, to solve the "tragedy" highlighted by Hardin (1968; Van Laerhoven and Ostrom 2007). This is one of the reasons for the spread of participatory conservation projects worldwide (Baland and Platteau 1996, Stevens 1997, Blaikie 2006), implemented by many kinds of development and conservation agencies (Alcorn 2005, Lowenhaupt Tsing et al. 2005, Blaikie 2006, Garnett et al. 2007). In these kinds of projects, the local beneficiary community is directly involved in the management of the natural resource that needs preserving. The objective is to attain simultaneously nature conservation and local economic development through the creation of a protected area. However, in many of these experiences in which a community manages a commons, the aid agency actually imposes on the community rules for resource exploitation, creating de facto a common-pool resource and the rules of the game (Garnett et al. 2007, Skjølsvold 2008). Thus, this creates an exogenous institution rather than an endogenous one.

Here, I formulate an agent-based model to explore the impact of different kinds of institutions on the state of a simulated forest and on the economic earning of the local logging community. I also explore the links between individual decision criteria about the share of forest that should be logged, the emergence of a community institution, and the interplay with an exogenously imposed institution. I investigate the issue of the crowding out of intrinsic motivation for environment conservation in the presence of imposed rules. I chose to simulate a forest management situation because many of the protected areas with participatory experiences in developing countries concern forested areas. However, one may extend the use of this model to interpret wider commons management phenomena, where a community of people must organize the harvesting of a shared resource that has an influence on their livelihood.

The paper is structured as follows. First, I explain what participatory conservation is and make reflections about the commons literature and the evolution of conservation strategies. Subsequently, I present the setup of the model. I model the situations, respectively, of open access, endogenous institutions, exogenous institutions, the presence of cheating, and the presence of enforcement. Finally, I discuss the results and conclude. The functioning and variables of the model are explained in detail in Appendix 1.

\footnotetext{
${ }^{1}$ Department of Economics and Statistics, University of Torino, Italy
} 


\section{THE COMMONS AND THE PARKS}

To understand and analyze the phenomenon of communitymanaged protected areas, there are two streams of literature that can be useful: first, the widely debated literature about the commons, and second, some history of protected areas.

Regarding the first issue, with his famous article of 1968 "The tragedy of the commons", Garrett Hardin started a long dispute about so-called common-pool resources. Hardin stated that if several individuals exploit the same resource and each of them has the goal of personal profit maximization, the only possible result will be the overharvesting of the resource, with each of the individuals being worse off. In the literature, it is now widely accepted that a community, under appropriate conditions, may be able to establish internal regulations leading to sustainable use of the limited resource, that is, not overstepping its carrying capacity and being compatible with its regrowth rate (Baland and Platteau 1996, Berkes and Folke 1998, Ostrom 1990, Van Laerhoven and Ostrom 2007). Institutions may solve the tragedy of the commons (Bravo 2011). This condition does not necessarily require the parcelization of the resource into individually owned parts or the imposition of rules by a public authority (Baland and Platteau 1996, McKean 2000, Dolšak and Ostrom 2003, Ostrom 2010, Poteete et al. 2010).

On the other hand, it is interesting to observe some patterns in the evolution of conservation policies. Historically, since the 19th century, the general approach to nature conservation has been the so-called "fine and fences" attitude: a full prohibition of the extraction of the resource that is supposed to be conserved (West et al. 2006, Brockington et al. 2008). Over the years, empirical evidence has emerged on the limitations of this approach (Dixon and Sherman 1990, Alcorn 2005, Haller and Galvin 2008), particularly in developing countries, where a high number of individuals and communities still base their livelihood on the extraction of natural resources through activities such as agriculture, livestock farming, harvesting, fishing, and logging (Haller and Galvin 2008). Conservation organizations have faced consistent problems of free-riding, illegal exploitation of resources by the local and external populations, and lack of enforcement (Gibson 1999, Berkes 2007). These main problems led to the development of "participatory conservation projects" (PC projects; Murphree 2002, Alcorn 2005), also known as "community-based natural resource management projects" (CBNMs), "integrated conservation and development projects" (ICDPs), and "community-based wildlife management projects" (CBWs). In these projects, the local community is organized in an institution involved in the management of the protected area and, in turn, has the right to exploit its resources to some degree. The aim is to promote both nature conservation and local economic development (Barrow et al. 2000, Roe et al. 2000, Hughes and Flintan 2001, Garnett et al. 2007, Tai 2007).

The promoters of these projects often use theoretical arguments provided by the numerous scholars of the commons: the selforganization of a community for the successful and sustainable management of a common-pool resource is feasible (Ostrom 1990, Blaikie 2006). Many different kinds of development agencies adopted this participatory approach: governmental organizations, local or international nongovernmental organizations (NGOs), and conservation organizations. Both organizations concerned with the environment and those concerned with local economic development started to share, in theory, this vision of combining nature protection with the fostering of local economic activities through community self-organization (Alcorn 2005, Lowenhaupt Tsing et al. 2005, Blaikie 2006).

There are a large number of case studies about communities that are collectively responsible for some natural resource (forests, pastures, fisheries, etc.), both successful and unsuccessful (Hughes and Flintan 2001, Alcorn 2005, Berkes 2007, Garnett et al. 2007, Galvin and Haller 2008, Vallino 2009). Very often, the commons that is collectively managed has, to some extent, the status of a protected area. ${ }^{1}$ For my purpose, "successful" refers to the achievement of two goals. First, the resource to be protected is allowed to renew itself at a sustainable rate. Second, the community improves its standard of living, measured mainly in monetary terms, through the PC project.

Alcorn (2005) and Lowenhaupt Tsing et al. (2005) identify two main kinds of PC projects: design mode and discovery mode.

“'Design mode' refers to situations where outsiders
identify a problem and design a solution. This model (...)
results in the typical community-based-conservation
project supported by Conservation Organizations (...).
'Discovery mode', on the other hand, refers to situations
where outsiders discover that local people have identified
a problem and designed a solution, and subsequently
assist local communities to legitimate their solution”
(Alcorn 2005:42).

Many subsequent case studies and my own field experience (Vallino 2009) appear to confirm this interpretation. Therefore, we can identify two main classes of PC projects. One class contains situations in which a community asked for the support of some external actors so as to get the recognition of some rights over a resource. The other involves contexts in which an external actor wanted to create a natural park and obtain the maximum possible collaboration from the local community. PC projects belonging to either one of these categories are actually mixed together in the literature (Table 1; Murphree 2002, Berkes et al 2003, Garnett et al 2007, Dansero 2010).

Scholars have discovered that institutions matter and may solve the tragedy of the commons. The authors particularly rely on endogenous institutions, that is to say, rules that emerge from the community members themselves (Bravo 2011, Agrawal 2007). For this reason, PC project designers focus their efforts on the community institution that will manage the threatened natural resource. Moreover, when analyzing the harms or benefits of PC projects, the community institution that manages the resource is often the object of the research whose goal is to detect the cause of failure or success of these initiatives (Leach et al. 1999, Platteau 2004, Joiris and Bigombè Logo 2008, Ruttan 2008).

The question of whether, when researchers look at a PC project, they are in a design mode or a discovery mode is mentioned in the literature (Grove 1989, Brosius et al. 2005, Blaikie 2006, Garnett et al. 2007, Ostrom 2007, Bromley 2008). However, it is surprising that no authors have engaged in a systematic study, either through statistical testing, theoretical modeling, or a case study approach, of whether and how the origin of the institution affects the project outcome or other variables that have already 
Table 1. Selected case studies of participatory forest management experiences in different countries, with information about their design or discovery mode and their degree of success. "Successful" refers to the achievement of two goals: the resource to be protected is allowed to renew itself at a sustainable rate, and the community improves its standard of living, measured mainly in monetary terms, through the participatory conservation project.

\begin{tabular}{|c|c|c|c|c|}
\hline Case study & Reference & $\begin{array}{l}\text { Project } \\
\text { mode }\end{array}$ & Degree of success & Main reasons for success/failure \\
\hline $\begin{array}{l}\text { Phong Nha Ke Bang } \\
\text { World Heritage, } \\
\text { Vietnam }\end{array}$ & Larsen 2008 & Design & $\begin{array}{l}\text { Half successful: fair biodiversity } \\
\text { conservation, but serious } \\
\text { livelihood problems }\end{array}$ & $\begin{array}{c}\text { Under different institutional } \\
\text { arrangements, de facto exclusion of } \\
\text { the local communities by access to } \\
\text { forest resources }\end{array}$ \\
\hline $\begin{array}{l}\text { Forêt Classée de la } \\
\text { Comoé-Lèraba, Burkina } \\
\text { Faso }\end{array}$ & Vallino 2009 & Design & $\begin{array}{l}\text { Half successful: fair biodiversity } \\
\text { conservation, but low income }\end{array}$ & $\begin{array}{l}\text { Local people's income decreased } \\
\text { because of lack of access to the } \\
\text { resources of the Reserve; decreased } \\
\text { access to the Reserve improved } \\
\text { conservation }\end{array}$ \\
\hline $\begin{array}{l}\text { Analavelona Forest, } \\
\text { Madagascar }\end{array}$ & Auer 2006 & Discovery & Fully successful & $\begin{array}{c}\text { Endogenously created community- } \\
\text { based rules and enforcement }\end{array}$ \\
\hline $\begin{array}{l}\text { Zombitse Forest, } \\
\text { Madagascar }\end{array}$ & Auer 2006 & Design & Unsuccessful & $\begin{array}{l}\text { Rules were imposed by the State } \\
\text { and were poorly enforced }\end{array}$ \\
\hline $\begin{array}{l}\text { Kayapó Indian Nation } \\
\text { Forest, Amazonia }\end{array}$ & Auer 2006 & Discovery & Fully successful & $\begin{array}{l}\text { Efficient indigenous skills in } \\
\text { protecting forests and extracting } \\
\text { resources at a sustainable rate }\end{array}$ \\
\hline $\begin{array}{l}\text { Amarakaeri Communal } \\
\text { Reserve, Peru }\end{array}$ & $\begin{array}{l}\text { Álvarez et al. } \\
2008\end{array}$ & Discovery & $\begin{array}{l}\text { Half successful: good biodiversity } \\
\text { conservation, but low income }\end{array}$ & $\begin{array}{l}\text { Local people's income decreased } \\
\text { because of lack of access to the } \\
\text { resources of the Reserve; decreased } \\
\text { access to the Reserve improved } \\
\text { conservation }\end{array}$ \\
\hline
\end{tabular}

been detected as relevant. In the popular institutional analysis and development (IAD) framework, Ostrom (2007) identifies four classes of variables that are decisive in determining the performance of the collective management of a common-pool resource: features of the resource system, of the resource units, of the users, and of the wider governance system. Government and NGOs appear only as one of the many features of the governance system category (Agrawal 2007, Ostrom 2007). No particular emphasis is posed on the fact that, in most cases, such organizations have triggered the community-based project.

More weight should be given to the variable indicating the nature of the institution governing the commons: endogenous or exogenous. This may decisively affect, at the origin, all the other relevant variables, and might (should) completely change the point of view of the researcher. Often, an NGO or external agency creates the situation of a common and the community responsible in order to pursue the goal of creating a park (Álvarez et al. 2008, Joiris and Bigombé Logo 2008, Roulet and Assenmaker 2008, Vallino 2009). This is what I call "the tragedy of the park". Garnett et al. (2007) emphasizes, "those seeking biodiversity conservation in poor countries are usually external stakeholders competing with both local values and other external stakeholders who place greater value on the resources they can extract."

Moreover, there is a kind of institutional engineering in $\mathrm{PC}$ projects linked to a protected area (Joiris and Bigombé Logo 2008, Skjølsvold 2008). External agencies enter communities and set up governance structures with little concern for existing institutional structures. In PC projects, the community has collective rights over the resources, and in this sense, the issue of endogenous rules for the commons management is relevant (Poteete and Welch 2004). However, the level at which the community should exploit the resource (the institution) is usually imposed by the external project designers (Galvin and Haller 2008, Dansero 2010, Ezzine de Blas et al. 2011). This fact must be acknowledged when a PC project is taken as a case study while studying a commons. Moreover, in the empirical and experimental literature, the risk of imposed institutions crowding out grassroots rules and motivations is mentioned (Frey 1994, Cardenas et al. 2000, Ostrom 2006, Bowles 2008).

The research questions underlying my work are thus as follows. Does the origin of the institution regulating access to the resource matter for explaining the results of a PC project? How do the interactions between individual rules, community endogenous institutions, and exogenously imposed institutions function?

\section{THE AGENT-BASED MODEL}

Adopting a theoretical approach, I use the tool of agent-based modeling to explore the consequences of different kinds of institutions for the state of a forest and the economic profit of its users. In general, agent-based models are suitable for analyzing social-ecological systems for the following reasons. They allow the introduction of consistent degrees of heterogeneity into the attributes of both the agents and their biophysical world, leading to a better theoretical understanding of the process of institutional emergence and change (Janssen and Ostrom 2007). Agent decisions are based on internal decision rules. The inclusion of agent interactions reflects the importance of communication 
in solving social dilemmas. Agent-based modeling is appropriate for describing complex adaptive systems and for observing the emergence of phenomena at higher scales than their parts (Bossel and Strobel 1978, Lansing and Kremer 1993, Epstein and Axtell 1996, Conte et al. 1997, Grimm 1999, Deadman et al. 2000, Holling 2001, Janssen and Ostrom 2006, Janssen 2007).

I model different scenarios of a community of people managing a forest. The model is implemented in NetLogo version 4.1 beta3 (Wilensky 2005; available on the OpenAbm platform: http://www. openabm.org/model/3004/version/1). I use an agent-based model created by Bravo (2011) as the initial scenario. The model gives information about the state of a forest and the monetary earning of the virtual agents after a certain period of time. Agents earn money when they log trees. These two variables correspond exactly to the observable objectives of PC projects. For this reason, it was convenient to start from this scenario to represent a forest governed by different kinds of institutions, some of which aim to represent a PC project situation. The model, in its different specifications, is described in detail in Appendix 1.

The focus of Bravo's (2011) model lies in the relationship between the internal (micro) states of the agents and the systems (macro) outcomes. Following North (2005), a strong relationship exists between the value system and the institutional framework that humans apply to coordinate their behaviors. Values, as other informal constraints, influence agents' behavior, telling them the appropriate action in a given situation. The agents' behavior determines the state of the world. In turn, the macro state of the world, i.e., competition among agents and the resource condition, influences the agents' values and thinking. As I will explain later, the fundamental mechanism of the simulation is based on this theory. Another extremely useful theoretical framework is that of Ensminger (1992), used also by Galvin and Haller (2008) and Haller (2010). The assumption is that institutions affect the economic performance of a system, that individuals realize this, and that they attempt to change an institution to serve their ends more effectively. Actors' bargaining power in the pre-existing institutional structure influences the relative success of different groups of individuals in getting the institutions they want (Ensminger 1992). External changes in the social, economic, and natural environment bring changes in the relative prices of common-pool resources, thus modifying their attractiveness. This has an effect on the local-level bargaining power of the actors who try to create institutional change (Haller 2010). In my model, this issue is reflected in the fact that in the endogenous-institution setting, the simulated local community owns sufficient bargaining power with respect to other stakeholders to self-determine the level of resource exploitation. In the exogenous-institution setting, this bargaining power declines because an external entity (the State or a development agency), being more powerful, determines the rules of the game. Therefore, the community loses the potential to modify the institution according to the changing environment. I next describe, in detail, each specification of the model.

\section{Baseline model: open access}

The baseline version of the model represents a community of people logging a forest in an open-access situation. Every member of the community takes decisions about logging or not logging according only to individual, and therefore, subjective values and visions of the world and on the basis of his own monetary earning.
Each simulation covers 2000 periods. Each period has 10 rounds. One round corresponds to one tick in NetLogo. One hundred agents operate on a toroidal surface that has been divided into patches. Each patch contains a different amount of tree biomass and may be logged in one round. If the patch is empty, biomass regrows with a positive probability (Janssen et al. 2008). An agent has three features. The first is called reference-trees and represents a subjective idea about the fraction of the initial total tree biomass that should ideally be conserved. It represents a personal level of importance that the agent gives to the environment in general. The value of this variable is heterogeneous among the agents, representing the fact that different people attach different degrees of significance to given issues (Jager and Janssen 2002). The second is minimal-cut and represents an operational value of the minimal level of tree biomass that a patch should have before being logged. At the beginning of the game, loggers believe that they can always cut. This variable will be updated during the simulation according to the state of the forest and the economic profit of the agent. The third feature is the payoff: It is assumed that when an agent logs a patch, he earns a monetary sum. In each round, he pays a fixed monetary charge. The payoff is calculated as the earning minus the cost. I assume that the exogenous cost parameter represents the general costs of displacement and monitoring the possibility of logging. I put this parameter as permanently "high" because I assume that poor rural communities have limited technical and technological means to travel and obtain information at a low cost (Baland and Platteau 1996, Vallino 2009). Agents move into the simulated forest and cut different quantities of trees according to their personal environmental values.

At the end of each period, there is an update of the subjective preferences of each agent about the right threshold of biomass quantity that should be present on a patch to help them decide whether to continue logging. Agents facing a payoff reduction become dissatisfied and are motivated to modify their subjective values and, therefore, their behavior. I assume here that agents have bounded rationality (Simon 1955, 1959, 1976) and act following a kind of trial-and-error process (Simon and Simon 1962) when they decide whether and how to update their operational values (minimal-cut). Moreover, this phase deals with the fact that people develop ways of learning and of understanding how a resource system reacts to any given behavior (Hutt 1970, Jager and Janssen 2002). Therefore, in the model, the reasoning process of a dissatisfied agent is as follows. If the share of the biomass left is lower than the agent's reference-trees (the share of the forest that should be conserved according to the agent's vision), he attributes the earning reduction to excessive cutting and will increase his own minimal-cut, becoming more "environmentalist," and vice-versa. In this way, the model is able to represent heterogeneity within agents who change values, decision-making strategies, and actions (Jager and Janssen 2002).

This mechanism is consistent with different streams of literature on mental models and human heuristics. Many authors state that individuals merge information from the situation that they face (here, the amount of biomass on a single patch and the amount of payoff) with pre-existing personal knowledge structures (here, the degree of importance given to forest preservation, i.e., reference-trees, which influences a change in the minimal-cut). In this way, they shape a mental model that gives them motivation and operational instructions for concrete action (Wagner and 
Hayes 2005, Jones et al. 2011, Lynam et al. 2012). Moreover, scholars agree on the fact that individuals experiencing resource depletion (Janssen and Ostrom 2007) or that are disappointed because of one another's behavior (Jager and Janssen 2002) become ready to modify their personal environmental values and hence their action. On the contrary, if the outcome of an agent's action is considered satisfactory, he will minimize his effort in the decision-making process, following a logic that Simon (1976) calls procedural rationality. Therefore, the agent will keep constant both his personal values and his operational rules in deciding his behavior (Jager and Janssen 2002).

At the end of the values update, a selection process among the agents takes place through the bankruptcy of unsuccessful agents. This concept is inspired by Janssen and Ostrom (2007). In my model, a copy of the most successful agent in terms of payoff replaces the agent with the lowest payoff. The new agent has the same value of the reference-tree variable as the previous agent and, therefore, has the same level of environmental motivation. There is a $1 \%$ probability of "mutation" in the form of "copy errors" or new entrants with innovative values. At the end of the selection process, all payoffs are put equal to zero and a new period starts. All the mechanisms described in the model remain the same for the further model extensions, apart from some small but important changes, as I explain next.

The model has some similarity with the human behavioural ecology (HBE) patch-choice model (Charnov 1976, Smith 1991). In both are agents that decide the level of resource extraction while reasoning at a patch level. However, in my model, agents do not take decisions using a maximization process but rather a trial-and-error heuristic. Moreover, the time spent by an agent on a patch is not as crucial a variable as it is in the HBE patch-choice model.

The results of the open-access version of the model show a complete depletion of the forest and very low payoffs for the agents. This implies that the selection process leads to the prevalence of agents with higher earnings who, in turn, believe that the correct state of the forest is one with less trees in it. Because we are in an open-access situation, with every agent deciding his behavior according only to his personal values, agents with a low minimal-cut will always log more. At the end, the typical tragedy of the commons occurs (Figs. 1, 2, and 3).

\section{Endogenous institution model}

In this version of the model, when the number of dissatisfied agents exceeds two-thirds of the population, loggers agree on a shared cutting rule. I chose the two-thirds threshold because it is either located between the extremes of unanimity or is controlled by a few (Janssen and Ostrom 2007, Bravo 2011). At the same time, it reflects the fact that institutional change is costly and a large consensus is needed (Ostrom 1990, 2005, Singleton and Taylor 1992, Janssen et al. 2008, Bravo 2011). The mean of the minimal-cut of each agent forms the new variable currentinstitution. This cutting rule becomes compulsory for every agent of the system. This part of the model acknowledges the fact that when individuals experience a depletion of the resource, they become willing not only to change their personal values and actions, but also to implement an institution that regulates the harvesting of the resource for the whole community (Berkes and Folke 1998, Johannes 2002, Berkes et al. 2003, Janssen and Ostrom 2007, Janssen et al. 2008, Bravo 2011).
Fig. 1. Example of the state of the forest in the openaccess model, represented in the graphic interface of NetLogo. This image symbolizes the mature forest at the setup phase of the simulation. Green indicates the amount of tree biomass: darker patches indicate lower tree biomass; lighter patches indicate higher tree biomass. Circles indicate loggers.

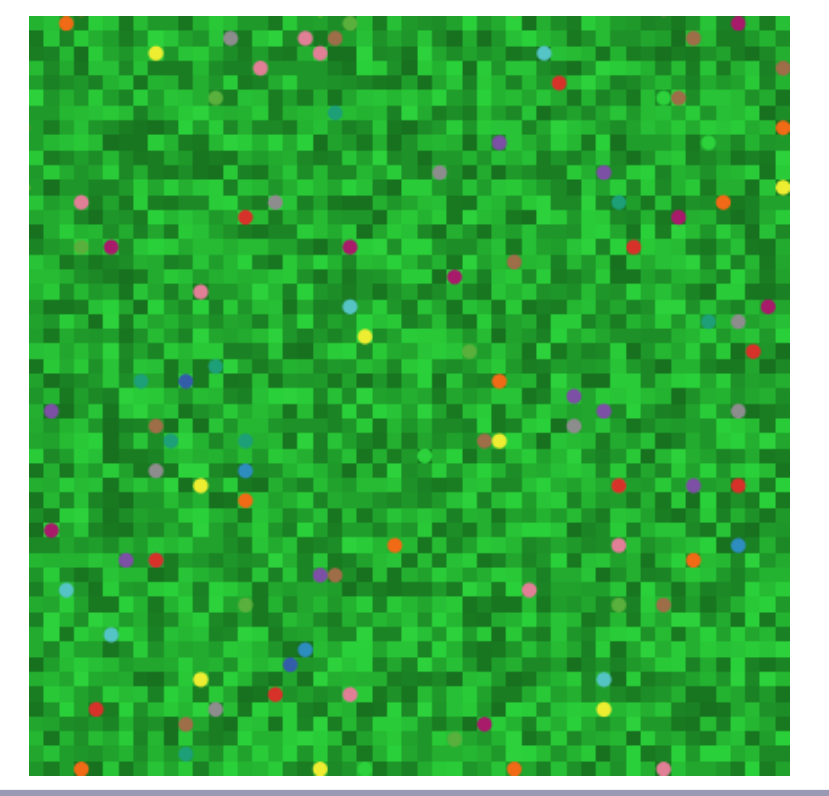

Fig. 2. Example of the state of the forest in the openaccess model, representing the forest after 1000 rounds. Green indicates the amount of tree biomass: darker patches indicate lower tree biomass; lighter patches indicate higher tree biomass. Black indicates complete removal of trees. Circles indicate loggers.

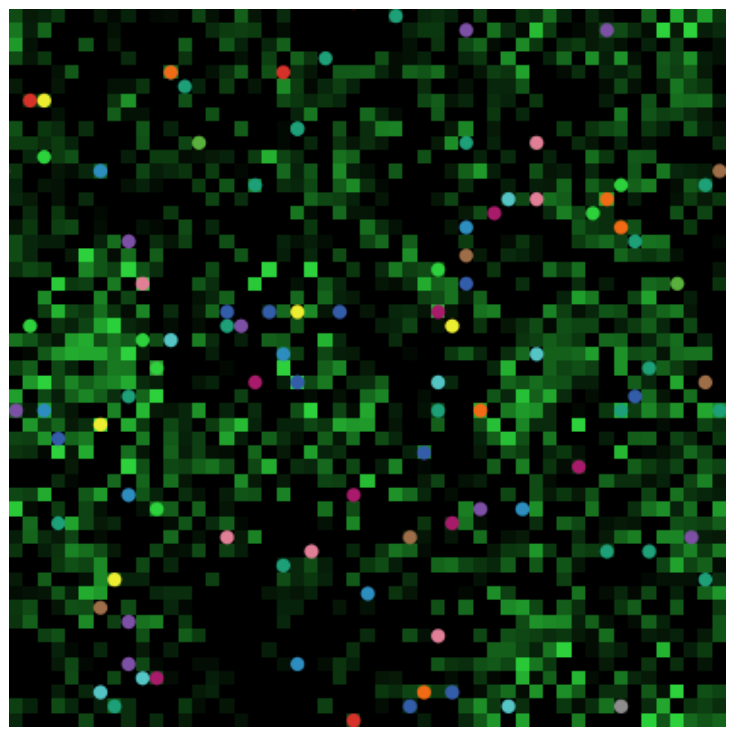


Fig. 3. Example of the state of the forest in the openaccess model, representing the forest after 20,000 rounds. Green indicates the amount of tree biomass: darker patches indicate lower tree biomass; lighter patches indicate higher tree biomass. Black indicates complete removal of trees. Circles indicate loggers. In this case, the forest is almost completely depleted.

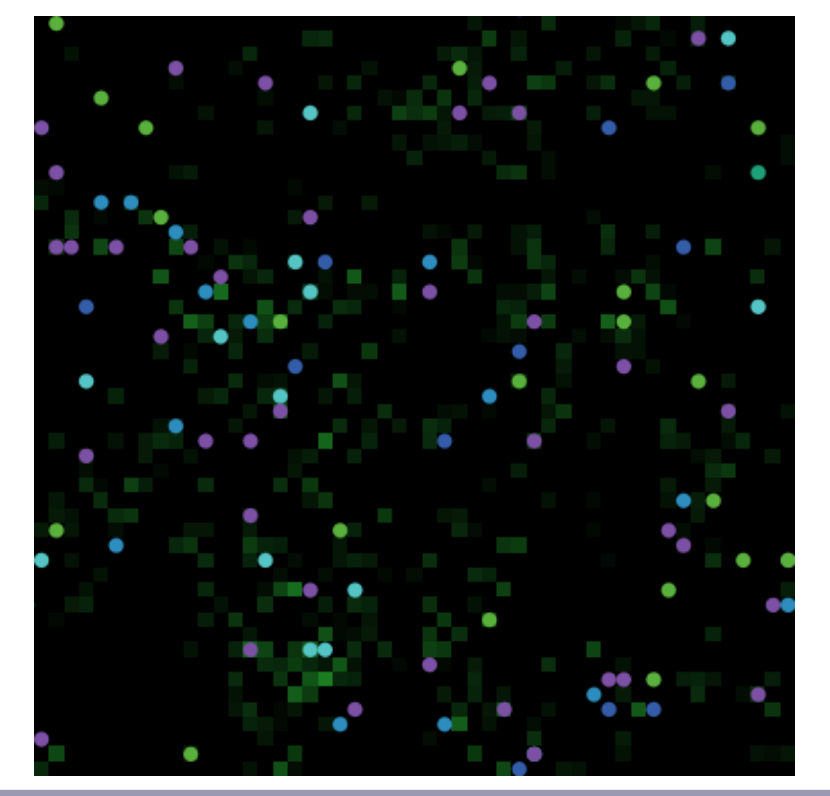

At this point, an additional criterion for agent dissatisfaction is in place: the distance between current-institution and minimal-cut. Therefore, if an agent faces a payoff reduction or if his personal environmental values are too far from the institutional rule in place, he is dissatisfied. Again, when a high number of dissatisfied agents are reached, the institutional rule is updated. The relatively high fraction of community members needed to change the institution reflects the fact that, in real situations of commonpool resource management, institutional change is usually costly and a large consensus is needed to reach this goal, at least when there is no subgroup of actors capable of imposing their regulation on the whole community (Singleton and Taylor 1992).

The results of this model version show much higher levels of total biomass and earning of agents compared with the open-access situation. These results are in line with the empirical literature (Ostrom 1990, National Research Council 2002, Berkes et al. 2003, Bravo 2011) and show that an institution endogenous to the community may solve the tragedy of the commons. The endogenously created institution makes the selection mechanism less effective in allowing the survival of more selfish characters among the agents and the defection of the others.

Turning the forest into a protected area: an exogenous institution In this version of the model, I represent a situation in which an exogenous entity like the State or an aid organization decides on the cutting threshold. In the model, this is symbolized by one added slider under the control of the researcher. The other features of the model, for example, the agents' reference-trees and minimal-cut, work the same way. The only difference is that dissatisfied agents are no longer able to update the cutting rule but must follow the imposed rule. Setting the cutting rule to a "high" level (e.g., level 9 in Table 2) represents a classical situation of a fortress-style protected area, where resource extraction is almost completely forbidden (Campbell and Vainio-Mattila 2003, Hayes 2006). In line with common-sense intuitions, the results of this simulation show a good state of the forest but a very low level of agent payoff. Otherwise, setting the cutting level to a "soft" rule, according to which it is possible to cut a high number of patches (e.g., level 2 in Table 2), the forest is depleted and the payoffs even become negative because, after a certain number of periods, agents do not find any more trees to cut. This outcome is similar to that in the open-access scenario.

\section{Introducing cheating}

At this point, the possibility of violating the cutting rules is introduced in the model. In both scenarios, i.e., endogenous and exogenous institutions, agents log a patch if either the cutting rule is fulfilled or the agent is dissatisfied. In both cases, the forest is completely logged, and the payoffs are negative. These results are a good reflection of studies about participatory conservation projects, either belonging to the discovery mode or the design mode. Illegal harvesters are relatively skilled in finding opportunities for logging timber illegally. This has been shown in many "paper parks" that have been created without paying sufficient attention to the level and type of monitoring (Gibson et al. 2005). Therefore, if a park is lacking in any form of control and rule enforcement, it is likely that forms of personal dissatisfaction will lead to free-riding behaviors.

\section{Introducing enforcement}

At this stage I introduce settings with rule violation and enforcement. The enforcement intensity is again determined in both cases by an external slider. I assume that enforcement intensity depends on the availability of resources to the institution in charge, being endogenous or exogenous to the community; it is not dependent on the performance of the participatory conservation experience. Punishment consists of the exclusion of those particular agents from the simulation.

\section{RESULTS AND DISCUSSION}

Results clearly show that enforcement matters (Table 2). This is in line with most of the general literature about natural resource management (Ostrom 1990, Baland and Platteau 1996, Gibson et al. 2005, Chhatre and Agrawal 2008) and about communitymanaged forests (Baland and Platteau 1996, Gibson et al. 2005, Chhatre and Agrawal 2008).

The most interesting outcome of the model concerns the variables minimal-cut and reference-trees, which represent the personal environmental values of the agents. In the last model version, with exogenous institution and enforcement, both of these variables reach zero, meaning that agents lose their own motivation to preserve some part of the forest. This also happens when shifting from the endogenous institution setting to the endogenous institution with enforcement scenario. This result may confirm some literature based on laboratory and field experiments showing that, in particular contexts, externally imposed regulation seems to crowd out intrinsic motivation. This is shown, for example, by Cardenas et al. (2000) through field experiments 
Table 2. Summary of simulation results for the seven different model specifications. Each specification of the model was run once.

\begin{tabular}{|c|c|c|c|c|c|c|c|c|}
\hline \multirow[b]{2}{*}{ Model specification } & \multicolumn{3}{|c|}{ Sliders $\dagger$} & \multicolumn{5}{|c|}{ Dependent variables: } \\
\hline & $\begin{array}{l}\text { Max-tree- } \\
\text { growth }\end{array}$ & Cost & ExogenInst§ & $\begin{array}{l}\text { Green } \\
\text { patches }\end{array}$ & $\begin{array}{c}\text { Total } \\
\text { biomass }\end{array}$ & Payoff & $\begin{array}{l}\text { Minimal- } \\
\text { cut }\end{array}$ & $\begin{array}{c}\text { Reference- } \\
\text { trees }\end{array}$ \\
\hline Open access & 50 & 5 & - & 0.05 & 0.09 & -40 & 4 & 0 \\
\hline Endogenous institution & 50 & 5 & - & 0.52 & 0.37 & 9.04 & 15.18 & 0.75 \\
\hline \multirow[t]{2}{*}{ Exogenous institution } & 50 & 5 & 2 & 0.05 & 0.01 & -35 & 14 & 0.4 \\
\hline & 50 & 5 & 9 & 0.42 & 0.28 & 3 & 9.3 & 0.56 \\
\hline Endogenous institution with rule violation & 50 & 5 & - & 0.02 & 0.005 & -39 & 0 & -0.21 \\
\hline \multirow[t]{2}{*}{ Exogenous institution with rule violation } & 50 & 5 & 2 & 0.04 & 0.009 & -37 & 0 & -0.16 \\
\hline & - & - & 9 & 0.44 & 0.14 & 15 & 0 & 0.3 \\
\hline $\begin{array}{l}\text { Endogenous institution with rule violation and } \\
\text { enforcement }\end{array}$ & 50 & 5 & - & 0.66 & 0.54 & 69 & 0 & 0.52 \\
\hline \multirow{2}{*}{$\begin{array}{l}\text { Exogenous institution with rule violation and } \\
\text { enforcement }\end{array}$} & 50 & 5 & 2 & 0.65 & 0.46 & 63 & 0 & 0.3 \\
\hline & - & - & 9 & 0.56 & 0.29 & 44 & 0 & 0.2 \\
\hline
\end{tabular}

$\dagger$ Sliders are variables that are controlled externally by the researcher: max-tree-growth $=$ maximum possible level of biomass per patch, cost $=$ fixed cost faced by agents for displacement and logging, ExogenInst = level of the exogenous cutting rule.

$\ddagger$ Dependent variables concern the state of the forest and the agents' characteristics. Green patches $=$ number of patches with biomass $>0$ at the end of the simulation divided by the total number of patches that had biomass $>0$ at the start of the simulation. Total biomass $=$ sum of the biomass of each patch at the end of the simulation divided by the sum of the biomass of each patch at the start of the simulation. Payoff $=$ an agent's earning when he logs a patch; positive values indicate a profit, whereas negative values indicate a loss. Minimal-cut $=$ an agent's vision about the minimal level of tree biomass that a patch should have before it is logged. Reference-trees $=$ an agent's idea about the fraction of initial tree biomass that should be conserved. Values for payoff, minimal-cut, and reference-trees means of the individual values at the end of the simulation. $\S$ Simulations with an exogenous institution have two possible imposed rules about the allowed cutting level. Level 2 represents a soft rule, meaning that agents can cut relatively often. Level 9 represents a strict rule, meaning that agents can cut infrequently.

in rural Colombia. These authors present evidence that such policies may be ineffective mainly because external control crowds out group-regarding behavior in favor of higher self-interest. The interpretation of these findings is very interesting. One may believe that the insufficient enforcement of these policies simply renders them ineffective. However, their simple existence may trigger the crowding-out of socially desirable behavior. Some authors suggest that external agencies, together with the local community, should concert the framing of the regulations, considering their needs and values, to avoid or, at least, to diminish the crowding-out effect. Similar reasoning is made by Bowles (2008), who, reviewing the wide behavioral experiments literature, shows how imposed economic incentives may be counterproductive, signaling that selfishness is an appropriate behavior. He explains this trend by the fact that people do not act only when inspired by economic motivations but also to present themselves as moral and respectable individuals in the eyes of their peers. Therefore, effective policies should combine incentives to the two dimensions of human motivation. Analogous conclusions are derived by Frey (1994).

Another important and counterintuitive outcome of the simulation regarding exogenous institution experiences is when the imposed cutting rule is at a soft level but enforcement is in place. This could reflect a participatory conservation project situation in which the rule about resource extraction is imposed, but without the adoption of a fortress approach, that is to say, a certain level (low or high) of resource extraction is allowed for the local population (Garnett et al. 2007). The simulation outcomes show very positive results. The number of green patches represents $65 \%$ of the initial level, and the total biomass is at $46 \%$ of the initial quantity. The agent payoffs are at their highest level up to now.
An interpretation of these results could be that if an external agent such as an NGO wants to impose a rule, it may be worth imposing a soft one but also investing a lot for the monitoring and enforcement of this rule. This solution may be superior to imposing a strict rule if resources for enforcement are not sufficient enough to monitor it anyway, as is the case for many participatory conservation projects in developing countries. On the one hand, this result may be surprising because, according to the mechanism of the model, one may think that if the rule allows frequent logging, agents will log indiscriminately. On the other hand, however, the fact that the agents are allowed to log at quite high levels at the beginning of the simulation makes their payoff sufficiently high to avoid the condition of dissatisfaction. Therefore, a low number of agents cheat by cutting owing to dissatisfaction. Moreover, the enforcement mechanism remains in place for those who still choose to violate the rule. In this way, forest depletion is prevented and, consequently, there is always a sufficient amount of trees to further satisfy the agents. The interplay among endogenous and exogenous institutions and enforcement, as is shown in the model, also reflects recent findings by Ostrom (2010:69), who states:

\footnotetext{
"Contrary to the presumption that external rules are the only way to make people overcome social dilemmas, experiments in rural settings in Colombia have generated diverse outcomes depending on context. Imposing external rules with low levels of monitoring and enforcement, like typically found in the rural areas where these experiments were conducted, did not improve rates of cooperation within groups as theoretically expected. (...) Lopez et al. (2009) found that letting subjects know how their decisions affected the group in framed field experiments and allowing informal sanctions was more effective than externally imposed regulation."
} 
Similar considerations can also be seen in the work of Baland and Platteau (1996), who state that external sanction systems are often necessary because of deficiencies of local enforcement mechanisms. To reach their goal, these mechanisms must be "escalating, flexible, and tolerant," and important decisions must be taken publicly (Baland and Platteau 1996:345).

For the purpose of my work, observing that the setting with the exogenous institution imposing a soft cutting rule and the presence of enforcement leads to very good outcomes in terms of the forest state and monetary payoffs, but to the disappearance of intrinsic agent motivations, may bring some interesting conclusions. This is the typical crowding-out effect described in the literature. Therefore, the success of this institutional setting is likely to be completely in the hands of the enforcement. This scenario may be fragile because resources and the effectiveness of monitoring and punishment activities might fluctuate. Policy makers should invest more in the actual exchange of information with the local community and look for mechanisms that actively involve their motivation and values about the importance of environment protection, even if these are heterogeneously distributed among the population and are not always particularly far-sighted.

Finally, I highlight an interesting result concerning the change of the variable cost. Following the approach of Ensminger (1992) regarding the importance of the relative price of the resource, I model situations in which, for some external reason, the price that agents must face when logging the trees may be high or low, instead of fixed, as it is in all other model specifications. Among all the possible results, one captures attention. In the presence of an exogenous institution that imposes a strict cutting rule (i.e., very low levels of logging are allowed) but that is somehow is able to decrease logging costs, both the state of the forest and the earning levels of the agents remain satisfying. One interpretation of this result is that if a forest faces high need of external preservation for biological reasons, one feasible way of maintaining community earnings sufficiently high might be that of decreasing logging costs for the allowed logging level. In this way, the classical trade-off between conservation and earning might be overcome, whereas in the previous model specification, the only way of maintaining agents' high earnings was to allow a relatively high level of logging. Again, of course, strong enforcement is necessary for the sustainability of this scenario.

\section{CONCLUSIONS}

Through the method of agent-based modeling, I created scenarios in which different kinds of institutional arrangements managed a forest commons. I observed the effects that the various institutions had on the state of the forest and on the monetary welfare of the forest users, and also looked at the consequences of the scenarios for the evolution of the personal environmental values of users.

A part of the outcome confirms the quantitative and qualitative empirical findings from the field and is quite intuitive. Its added value lies in the fact that the related agent-based model offers a formalization of the described processes and allows the dynamics of the mechanism to be tracked. This holds for the following results. In an open-access situation, there is forest depletion and low profit levels for the forest users. In a situation where the users' community is able to create an endogenous institution to govern resource extraction from the forest, the model shows good outcomes regarding both the state of the forest and the profit levels. If an exogenously determined institution that has the aim of preserving the forest is in place, the results show that it will succeed in this goal; however, the payoffs of the forest users will be very low, leading to a high number of dissatisfied individuals. The presence of enforcement clearly improves the outcomes, both with an endogenous or exogenous institution.

The next following results are counterintuitive, even if they are supported by the experimental literature. First, an imposed institutional rule from the outside may crowd out the intrinsic environmental motivations of the agents. Second, in the exogenous institution setting, the best outcomes in terms of forest condition and agent payoffs are given when the imposed rule is a soft one and enforcement is in place.

In summary, after comparing different scenarios in which the forest is managed by different kinds of institutions, the best outcomes in terms of the sustainability of forest logging and of the community members' earnings occur under two kinds of settings: (1) when the forest commons is managed by an institution that has been created endogenously by the community and is able to adapt from time to time to changes in the community's needs and values to minimize dissatisfaction and therefore incentives to violate the rule, and that provides local monitoring and enforcement; and (2) if an imposed institution is in place, without the possibility of being updated, it is more effective to choose a soft resource extraction rule but invest more in the enforcement of that rule than it is to impose a strict rule.

Regarding the first situation, there are successful cases in which locally devised rules recognized on a higher institutional level give back trust to the local community. Chabwela and Haller (2010) present the case of a participatory co-management process in the Kafue Flats in Zambia. In this case, the Department of Fisheries, after facing a financial and institutional crisis, engaged in a process of developing locally based by-laws for the joint management of fisheries. The results are quite successful. According to the authors, one of the reasons why this type of governance may be successful lies in the fact that a sense of ownership of resource management on the local level is reestablished, allowing local commitment to monitoring, which is otherwise costly. In other examples, Haller et al. (2013) identify initiatives that aim to give back a sense of ownership, referring to local land and its resources in Tanzania.

Further research in different directions would be very useful. First, additional variations of the model should be built. For example, punishment could be turned into a payoff reduction for those violating the rule. It would be worth investigating the role of social influence among the agents and its effects on their propensity to cheat. It would also be interesting to simulate the so-called buffer zones around protected areas. Studies indicate that forcing the concentration of resource extraction in these zones may be counterproductive because resource depletion is reached more rapidly than when extraction is dispersed throughout the whole protected area (Vallino 2009).

Second, it would be useful to incorporate issues of changes in the political and economic conditions of the environment in which agents operate. These kinds of changes would lead to a change in 
the relative price of the natural resource (Ensminger 1992). In a future agent-based model, the issue of bargaining power could be deepened by modeling intermediate ways of rule creation between purely endogenous or exogenous. For example, in an exogenous rule setting, it is feasible to give the possibility to the community to modify the rule to different degrees, depending on the kind of external agent in place. Moreover, it is possible to simulate changes in the environment in which agents operate to influence the earning and cost levels of the loggers, to represent changes in relative prices. Thus, the effects of relative price changes on institutional performance could be observed.

Finally, it is crucial to conduct a field experiment with forest users of a participatory conservation project to introduce actual values in the variables of the model and test the consistency of the intuitions presented here.

\section{Footnotes}

1. According to the International Union for Conservation of Nature (1994:7), a protected area is "an area of land or sea especially dedicated to the protection and maintenance of biological diversity, and of natural and associated cultural resources, and managed through legal or other effective means." The International Union for Conservation of Nature established six categories of protected areas, according to the degree to which resource extraction is allowed within the conserved zone (IUCN 1994).

Responses to this article can be read online at: http://www.ecologyandsociety.org/issues/responses. $\mathrm{php} / 6242$

\section{Acknowledgments:}

I sincerely thank the following people for helpful comments and ideas: Silvana Dalmazzone, Pietro Terna, Giangiacomo Bravo, Jean-Philippe Platteau, Gani Aldashev, Marc Bellemare, the members of the CRED workshop at the University of Namur, Cedric Vermeulen, Marco Janssen, Michael Schoon, and the PhD students in Economics at the University of Torino. A particular thank you goes to three anonymous reviewers for their valuable comments. Finally, I thank Collegio Carlo Alberto for financial support.

\section{LITERATURE CITED}

Agrawal, A. 2007. Forest, governance, and sustainability: common property theory and its contributions. International Journal of the Commons 1(1):111-136.

Alcorn, J. B. 2005. Dances around the fire: conservation organizations and community-based natural resource management. Pages 37-68 in J. P. Brosius, A. Lowenhaupt Tsing, and C. Zerner, editors. Communities and conservation: histories and politics of community-based natural resource management. Altamira, Walnut Creek, California, USA.

Álvarez, A., J. Alca, M. Galvin, and A. García. 2008. The difficult invention of participation in the Amarakaeri Communal Reserve, Peru. Pages 111-144 in M. Galvin and T. Haller, editors. People, protected areas and global change: participatory conservation in
Latin America, Africa, Asia and Europe. Swiss National Centre of Competence in Research North-South, University of Bern, Bern, Switzerland.

Auer, M. 2006. Contexts, multiple methods, and values in the study of common-pool resources. Journal of Policy Analysis and Management 25(1):215-227. http://dx.doi.org/10.1002/pam.20163

Baland, J. M., and J.-P. Platteau. 1996. Halting degradation of natural resources. Is there a role for rural communities? Food and Agriculture Organization of the United Nations, Rome, Italy. [online] URL: http://www.fao.org/docrep/x5316e/x5316e00.htm.

Barrow, E., H. Gichohi, and M. Infield. 2000. Rethoric or reality? $A$ review of community conservation policy and practice in East Africa. Evaluating Eden Series 5. International Institute for Environment and Development (IIED), London, UK. [online] URL: https://portals.iucn.org/library/node/7807.

Berkes, F. 2007. Community-based conservation in a globalized world. Proceedings of the National Academy of Sciences 104 (39):15188-15193. http://dx.doi.org/10.1073/pnas.0702098104

Berkes, F., J. Colding, and C. Folke, editors. 2003. Navigating social-ecological systems: building resilience for complexity and change. Cambridge University Press, Cambridge, UK. http://dx. doi.org/10.1017/CBO9780511541957

Berkes, F., and C. Folke, editors. 1998. Linking social and ecological systems: management practices and social mechanisms for building resilience. Cambridge University Press, Cambridge, UK.

Blaikie, P. 2006. Is small really beautiful? Community-based natural resource management in Malawi and Botswana. World Development 34(11):1942-1957. http://dx.doi.org/10.1016/j. worlddev.2005.11.023

Bossel, H., and M. Strobel. 1978. Experiments with an "intelligent" world model. Futures 10(3):191-212. http://dx.doi. org/10.1016/0016-3287(78)90102-7

Bowles, S. 2008. Policies designed for self-interested citizens may undermine "the moral sentiments": evidence from economic experiments. Science 320:1605-1609. http://dx.doi.org/10.1126/ $\underline{\text { science. } 1152110}$

Bravo, G. 2011. Agents' beliefs and the evolution of institutions for common-pool resource management. Rationality and Society 23(1):117-152. http://dx.doi.org/10.1177/1043463110387268

Brockington, D., R. Duffy, and J. Igoe. 2008. Nature unbound: conservation, capitalism and the future of protected areas. Earthscan, London, UK.

Bromley, D. W. 2008. Resource degradation in the African commons: accounting for institutional decay. Environment and Development Economics 13(5):539-563. http://dx.doi.org/10.1017/ $\underline{\mathrm{S} 1355770 \mathrm{X} 08004427}$

Brosius, J. P., A. Lowenhaupt Tsing, and C. Zerner, editors. 2005. Communities and conservation: histories and politics of community-basednatural resource management. Altamira, Walnut Creek, California, USA.

Campbell, L. M., and A. Vainio-Mattila. 2003. Participatory development and community-based conservation: opportunities 
missed for lessons learned? Human Ecology 31(3):417-437. http:// dx.doi.org/10.1023/A:1025071822388

Cardenas, J. C., J. Stranlund, and C. Willis. 2000. Local environmental control and institutional crowding-out. World Development 28(10):1719-1733. http://dx.doi.org/10.1016/S0305-750X (00)00055-3

Chabwela, H. N., and T. Haller. 2010. Governance issues, potentials and failures of participative collective action in the Kafue Flats, Zambia. International Journal of the Commons 4 (2):621-642.

Charnov, E. L. 1976. Optimal foraging, the marginal value theorem. Theoretical Population Biology 9(2):129-136. http://dx. doi.org/10.1016/0040-5809(76)90040-X

Chhatre, A., and A. Agrawal. 2008. Forest commons and local enforcement. Proceedings of the National Academy of Sciences 105(36):13286-13291. http://dx.doi.org/10.1073/pnas.0803399105

Conte, R., R. Hegselmann, and P. Terna, editors. 1997. Simulating social phenomena. Springer, Berlin, Germany. http://dx.doi. org/10.1007/978-3-662-03366-1

Dansero, E., editor. 2010. Cooperazione decentrata, protezione della natura e pratiche territoriali: rappresentazioni a confronto tra Nord e Sud del mondo. Un 'indagine a partire dall' analisi delle esperienze di partenariato tra aree protette del Piemonte e della Valle d'Aosta con i paesi in via di sviluppo. Fondazione CRTProgetto Alfieri, Dipartimento Interateneo Territorio, Politecnico e Università di Torino, Regione Piemonte-Settore Aree Protette, Università della Valle d'Aosta, Torino, Italy.

Deadman, P. J., E. Schlager, and R. Gimblett. 2000. Simulating common pool resource management experiments with adaptive agents employing alternate communication routines. Journal of Artificial Societies and Social Simulations 3(2): 2. [online] URL: http://jasss.soc.surrey.ac.uk/3/2/2.html.

Dixon, J. A., and P. B. Sherman. 1990. Economics of protected areas: a new look at benefits and costs. Island Press, Washington, D.C., USA.

Dolšak, N., and E. Ostrom. 2003. The commons in the new millennium: challenges and adaptation. MIT Press, Cambridge, Massachusetts, USA.

Ensminger, J. 1992. Making a market: the institutional transformation of an African society. Cambridge University Press, Cambridge, UK.

Epstein, J. M., and R. Axtell. 1996. Growing artificial societies: social science from the bottom up. Brookings Institution Press, Washington, D.C., USA.

Ezzine de Blas, D., M. Ruiz-Pérez, and C. Vermeulen. 2011. Management conflicts in Cameroonian community forests. Ecology and Society 16(1): 8. [online] URL: http://www. ecologyandsociety.org/vol16/iss1/art8/.

Frey, B. S. 1994. How intrinsic motivation is crowded out and in. Rationality and Society 6(3):334-352. http://dx.doi. org/10.1177/1043463194006003004

Galvin, M., and T. Haller, editors. 2008. People, protected areas and global change: participatory conservation in Latin America,
Africa, Asia and Europe. Swiss National Centre of Competence in Research North-South, University of Bern, Bern, Switzerland.

Garnett, S. T., J. Sayer, and J. Du Toit. 2007. Improving the effectiveness of interventions to balance conservation and development: a conceptual framework. Ecology and Society 12 (1): 2. [online] URL: http://www.ecologyandsociety.org/voll2/ iss $1 / \operatorname{art} 2 /$.

Gibson, C. C. 1999. Politicians and poachers: the political economy of wildlife policy in Africa. Cambridge University Press, Cambridge, UK. http://dx.doi.org/10.1017/CBO9780511625640

Gibson, C. C., J. T. Williams, and E. Ostrom. 2005. Local enforcement and better forests. World Development 33(2):273-284. http://dx.doi.org/10.1016/j.worlddev.2004.07.013

Grimm, V. 1999. Ten years of individual-based modelling in ecology: What have we learned and what could we learn in the future? Ecological Modelling 115(2-3):129-148. http://dx.doi. org/10.1016/S0304-3800(98)00188-4

Grove, R. 1989. Scottish missionaries, evangelical discourses and the origins of conservation thinking in Southern Africa 18201900. Journal of Southern African Studies 15(2):163-187. http:// dx.doi.org/10.1080/03057078908708196

Haller, T., editor. 2010. Disputing the floodplains: institutional change and the politics of resource management in African wetlands.

Brill, Leiden, The Netherlands. http://dx.doi.org/10.1163/ ej. $9789004185326 . \mathrm{i}-454$

Haller, T., G. Fokou, G. Mbeyale, and P. Meroka. 2013. How fit turns into misfit and back: institutional transformations of pastoral commons in African floodplains. Ecology and Society 18 (1): 34. http://dx.doi.org/10.5751/ES-05510-180134

Haller, T., and M. Galvin. 2008. Introduction: the problem of participatory conservation. Pages 13-36 in M. Galvin and T. Haller, editors. People, protected areas and global change: participatory conservation in Latin America, Africa, Asia and Europe. Perspectives of the Swiss National Centre of Competence in Research North-South, University of Bern, Bern, Switzerland.

Hardin, G. 1968. The tragedy of the commons. Science 162 (3859):1243-1248. http://dx.doi.org/10.1126/science.162.3859.1243

Hayes, T. M. 2006. Parks, people, and forest protection: an institutional assessment of the effectiveness of protected areas. World Development 34(12):2064-2075. http://dx.doi.org/10.1016/ j.worlddev.2006.03.002

Holling, C. S. 2001. Understanding the complexity of economic, ecological, and social systems. Ecosystems 4(5):390-405. http:// dx.doi.org/10.1007/s10021-001-0101-5

Hughes, R., and F. Flintan. 2001. Integrating conservation and development experience: a review and bibliography of the ICDP literature. Biodiversity and Livelihoods Issues 3. International Institute for Environment and Development, London, UK. [online] URL: http://pubs.iied.org/9080IIED.html?s=BL.

Hutt, C. 1970. Specific and diverse exploration. Advances in Child Development and Behavior 5:119-180. http://dx.doi.org/10.1016/ $\underline{\text { S0065-2407(08)60466-8 }}$ 
International Union for the Conservation of Nature. 1994. Guidelines for protected area management categories. IUCN, Gland, Switzerland.

Jager, W., and M. A. Janssen. 2002. Using artificial agents to understand laboratory experiments of common-pool resources with real agents. Pages 75-102 in M. A. Janssen, editor. Complexity and ecosystem management: the theory and practice of multi-agent systems. Edward Elgar, Cheltenham, UK.

Janssen, M. A. 2007. Coordination in irrigation systems: an analysis of the Lansing-Kremer model of Bali. Agricultural Systems 93(1-3):170-190. http://dx.doi.org/10.1016/j.agsy.2006.05.004

Janssen, M. A., R. L. Goldstone, F. Menczer, and E. Ostrom. 2008. Effect of rule choice in dynamic interactive spatial commons. International Journal of the Commons 2(2):288-312.

Janssen, M. A., and E. Ostrom. 2006. Governing social-ecological systems. Pages 1465-1510 in L. Tesfatsion and K. L. Judd, editors. Handbook of computational economics: agent-based computational economics. Volume 2. North-Holland Elsevier, Amsterdam, The Netherlands. http://dx.doi.org/10.1016/S1574-0021(05)02030-7

Janssen, M. A., and E. Ostrom. 2007. Adoption of a new regulation for the governance of common-pool resources by heterogeneous population. Pages 60-96 in J.-M. Baland, P. Bardhan, and S. Bowels, editors. Inequality, cooperation and environmental sustainability. Princeton University Press, Princeton, USA.

Janssen, M. A., and E. Ostrom. 2008. TURFS in the lab: institutional innovation in real time dynamic spatial commons. Rationality and Society 20(4):371-397. http://dx.doi. org/10.1177/1043463108096786

Johannes, R. E. 2002. Did indigenous conservation ethics exist? Traditional Marine Resource Management and Knowledge Information Bulletin 14:3-7. [online] URL: http://www.spc.int/ coastfish/en/publications/bulletins/traditional-management/208traditional-information-bulletin-14.html.

Joiris, D. V., and P. Bigombé Logo. 2008. Dynamiques participatives et développement local dans le Bassin congolais. Des rendez-vous manqués? Pages 21-37 in P. A. Roulet and P. Assenmaker, editors. Gouvernance et environnement en Afrique Centrale: le modèle participatif en question. Musée Royale de l'Afrique Centrale, Tervuren, Belgium.

Jones, N. A., H. Ross, T. Lynam, P. Perez, and A. Leitch. 2011. Mental models: an interdisciplinary synthesis of theory and methods. Ecology and Society 16(1): 46. [online] URL: http:// www.ecologyandsociety.org/vol16/iss1/art46/.

Lansing, J. S., and J. N. Kremer. 1993. Emergent properties of Balinese water temple networks: coadaptation on a rugged fitness landscape. American Anthropologist 95(1):97-114. http://dx.doi. org/10.1525/aa.1993.95.1.02a00050

Larsen, P. B. 2008. Linking livelihoods and protected area conservation in Vietnam: Phong Nha Ke Bàng World Heritage, local futures? Pages 431-470 in M. Galvin and T. Haller, editors. People, protected areas and global change: participatory conservation in Latin America, Africa, Asia and Europe.
Perspectives of the Swiss National Centre of Competence in Research North-South, University of Bern, Bern, Switzerland.

Leach, M., R. Mearns, and I. Scoones. 1999. Environmental entitlements: dynamics and institutions in community-based natural resource management. World Development 27(2):225-247. http://dx.doi.org/10.1016/S0305-750X(98)00141-7

Lopez, M. C., J. J. Murphy, J. M. Spraggon, and J. K. Stranlund. 2009. Comparing the effectiveness of regulation and pro-social emotions to enhance cooperation: experimental evidence from fishing communities in Colombia. Economic Inquiry 50 (1):131-142. http://dx.doi.org/10.1111/j.1465-7295.2010.00344.x

Lowenhaupt Tsing, A., J. P. Brosius, and C. Zerner. 2005. Introduction: raising questions about communities and conservation. Pages 1-36 in J. P. Brosius, A. Lowenhaupt Tsing, and C. Zerner, editors. Communities and conservation: histories and politics of community-based natural resource management. Altamira, Walnut Creek, California, USA.

Lynam, T., R. Mathevet, M. Etienne, S. Stone-Jovicich, A. Leitch, N. Jones, H. Ross, D. Du Toit, S. Pollard, H. Biggs, and P. Perez. 2012. Waypoints on a journey of discovery: mental models in human-environment interactions. Ecology and Society 17(3): 23. http://dx.doi.org/10.5751/ES-05118-170323

McKean, M. A. 2000. Common property: What is it, what is good for, and what makes it work? Pages 27-55 in C. C. Gibson, M. A. McKean, and E. Ostrom, editors. People and forests: communities, institutions, and governance. MIT Press, Cambridge, USA.

Murphree, M. W. 2002. Protected areas and the commons. Common Property Resource Digest 60:1-3.

National Research Council. 2002. The drama of the commons. National Academies Press, Washington, D.C., USA.

North, D. C. 2005. Understanding the process of economic change. Princeton University Press, Princeton, New Jersey, USA.

Ostrom, E. 1990. Governing the commons: the evolution of institutions for collective action. Cambridge University Press, Cambridge, UK. http://dx.doi.org/10.1017/CBO9780511807763

Ostrom, E. 2005. Understanding institutional diversity. Princeton University Press, Princeton, New Jersey, USA.

Ostrom, E. 2006. The value-added of laboratory experiments for the study of institutions and common-pool resources. Journal of Economic Behavior \& Organization 61(2):149-163. http://dx.doi. org/10.1016/j.jebo.2005.02.008

Ostrom, E. 2007. A diagnostic approach for going beyond panaceas. Proceedings of the National Academy of Sciences 104 (39):15181-15187. http://dx.doi.org/10.1073/pnas.0702288104

Ostrom, E. 2010. Revising theory in light of experimental findings. Journal of Economic Behavior \& Organization 73 (1):68-72. http://dx.doi.org/10.1016/j.jebo.2008.11.008

Platteau, J.-P. 2004. Monitoring elite capture in communitydriven development. Development and Change 35(2):223-246. http://dx.doi.org/10.1111/j.1467-7660.2004.00350.x 
Poteete, A. R., and D. Welch. 2004. Institutional development in the face of complexity: developing rules for managing forest resources. Human Ecology 32(3):279-311. http://dx.doi. org/10.1023/B:HUEC.0000028083.29437.ac

Poteete, A. R., M. A. Janssen, and E. Ostrom. 2010. Working together: collective action, the commons, and multiple methods in practice. Princeton University Press, Princeton, USA.

Roe, D., J. Mayers, M. Grieg-Gran, A. Kothari, C. Fabricius, and R. Hughes. 2000. Evaluating Eden: exploring the myths and realities of community-based wildlife management. International Institute for Environment and Development, London, UK. [online] URL: $\underline{\text { http://pubs.iied.org/7810IIED.html?a=D. }}$

Roulet, P. A., and P. Assenmaker, editors. 2008. Gouvernance et environnement en Afrique Centrale: le modèle participatif en question. Musée Royale de l'Afrique Centrale, Tervuren, Belgium.

Ruttan, L. M. 2008. Economic heterogeneity and the commons: effects on collective action and collective goods provisioning. World Development 36(5):969-985. http://dx.doi.org/10.1016/j. worlddev.2007.05.005

Simon, H. A. 1955. A behavioral model of rational choice. Quarterly Journal of Economics 69(1):99-118. http://dx.doi. org/10.2307/1884852

Simon, H. A. 1959. Theories of decision-making in economics and behavioral science. American Economic Review 49 (3):253-283.

Simon, H. A. 1976. From substantive to procedural rationality. Pages 129-148 in S. Latsis, editor. Method and appraisal in economics. Cambridge University Press, Cambridge, UK. http:// dx.doi.org/10.1017/CBO9780511572203.006

Simon, H. A., and P. A. Simon. 1962. Trial and error search in solving difficult problems: evidence from the game of chess. Behavioral Science 7(4):425-429. http://dx.doi.org/10.1002/ bs.3830070402

Singleton, S., and M. Taylor. 1992. Common property, collective action and community. Journal of Theoretical Politics 4 (3):309-324. http://dx.doi.org/10.1177/0951692892004003004

Skjølsvold, T. M. 2008. Institutional conflicts as results of institutional design - Can they be avoided? 12th Biennial Conference of the International Association of the Study of the Commons (July 2008). University of Gloucestershire, Cheltenham, UK.

Smith, E. A. 1991. Inujjuamiut foraging strategies: evolutionary ecology of an Arctic hunting economy. Aldine de Gruyter, Hawthorne, New York, USA.

Stevens, S., editor. 1997. Conservation through cultural survival: indigenous peoples and protected areas. Island Press, Washington, D.C., USA.

Tai, H.-S. 2007. Development through conservation: an institutional analysis of indigenous community-based conservation in Taiwan. World Development 35(7):1186-1203. http://dx.doi. org/10.1016/j.worlddev.2006.09.015

Vallino, E. 2009. Community based management of a protected area: the case of GEPRENAF in Burkina Faso. International
Journal of Social Forestry 2(1):24-42. [online] URL: http://www. ijsf.org/dat/art/vol02/ijsf_vol2_nol 02 elena protected area burkinafaso. pdf.

Van Laerhoven, F., and E. Ostrom. 2007. Traditions and trends in the study of the commons. International Journal of the Commons 1(1):3-28.

Wagner, W., and N. Hayes. 2005. Everyday discourse and common sense: the theory of social representations. Palgrave Macmillan, New York, New York, USA.

West, P., J. Igoe, and D. Brockington. 2006. Parks and peoples: the social impact of protected areas. Annual Review of Anthropology 35:251-277. http://dx.doi.org/10.1146/annurev. anthro.35.081705.123308

Wilensky, U. 2005. NetLogo. Center for Connected Learning and Computer-Based Modeling, Northwestern University, Evanston, Illinois, USA. [online] URL: http://ccl.northwestern.edu/ netlogo/. 


\section{APPENDIX}

\section{Description of the agent based model.}

\section{The baseline model: open access}

Variables utilized in every version of the model are described in detail in Table A.1. In the baseline model, the state of the world has the following features. 100 agents operate on a regular lattice of degree $l=8$. The lattice has the structure of an $m \times m$ toroidal surface, with $m=50$. The surface is divided in patches. Each patch is a forest area that can be logged in one round. Patches have the attribute trees, which belongs to the [0, max-tree-growth] interval. It represents the total tree biomass present in a given moment in the patch and, if its value is higher than zero, it takes a green colour. max-tree-growth is the maximum possible level of biomass per patch, and it is controlled by an external slider. This choice is made in order to have the possibility to represent different kinds of forest, containing more or less vegetation. At the beginning of the simulation the forest is mature, with the value of trees randomly distributed in the [ $1 / 2$ max-tree-growth, max-tree-growth] interval. If not logged, biomass in each patch grows at the fixed rate of 0.5 units per round up to the point where they reach max-tree-growth. If the patch is empty, biomass regrows with a probability depending on the state of the neighbouring patches, according to the function

growth-prob *((living-neighbours +1$) / 9)$

where growth-prob is the basic regrowth probability and has the value of 0.05 , living-neighbours is the number of non-empty neighbour patches and 9 means $8+1$, with 8 being the number of neighbour patches. This concept of neighbourhood is analogous to that used in Janssen and Ostrom (2006). This means that if all the neighbour patches are green, the regrowth probability of an empty patch is 0.05 , while if it is surrounded by empty patches the probability will be 0.005555 . This function is used by Janssen et al. (2008) for the "spatial commons experiments". One difference is that here the regrowth probability is strictly above zero because of mechanisms, assumed to be present, such as the natural recovery capacity due to seed conservation in the soil and seed dispersion by animals.

Each agent has three features. The first is called reference-trees and represents a subjective idea about the fraction of the initial tree biomass that should be ideally conserved. This symbolizes a cognitive model that each agent has about the "right" state of the world. At the beginning of each round this is drawn randomly from a normal distribution having mean 0.5 and standard deviation 0.25 and it remains subsequently constant. The second is minimal-cut and represents a preference about the minimal level of tree biomass that a patch should have in order to be logged. For every agent it is equal to zero when agents enter the game. This conditions means that at the beginning of the game loggers believe that they can always cut. This variable will update during the simulation according to the state of the forest and to the economic profit of the agent. I will describe this mechanism later. The third feature is the payoff : it is assumed that when an agent logs a patch he earns a monetary profit. At the beginning of the simulation payoff is equal to zero for every agent. The execution of the model operates as follows. Each simulation covers 2000 periods. Each period has 10 rounds. One round corresponds to one "tick" in NetLogo. In every round agents move within the simulated forest and each of them pays a fixed monetary charge. This variable is called 
cost and it is controlled by an external slider, so that it is possible to assume high or low costs for displacement and logging in general. When an agent arrives on a patch he has to decide if logging or not. If the condition

\section{[trees] of patch-here > minimal-cut}

is true, than the agent cuts and the quantity of trees is added to his payoff. If the condition is not true, the agents controls if any of the neighbor patches has biomass above that threshold. If he finds any, he moves on one of these patches, pays the fixed charge and realizes no earning in the current round. If none of the patches has sufficient biomass, the agents move randomly and earns no profits. The payoff of each agent is given by the difference between his earnings and costs.

At the end of each period there is an update of the subjective preferences of each agent about the right threshold of biomass quantity that should be present on a patch in order to decide whether to $\log$ or not. If the current payoff is higher or equal to that of the previous round, the agent maintains his minimal-cut. This means that if the agent is satisfied about his profit from the logging activity, he has no reason to modify his opinion about the importance of preserving part of the forest intact. Otherwise, the agent changes his minimal-cut with a probability $q$ :

$q$ (payoff - old-payoff) / (abs payoff + abs old-payoff)

where old-payoff is the payoff of the previous round and abs means "absolute value". A random extraction determines if the agent will actually change his minimal-cut. If this happens his minimalcut is modified according to his reference-trees. More specifically, if the total number of green patches is higher than the fraction that should ideally be conserved according to the agent's vision (reference-tree), the agent decreases his minimal-cut by a random value in the interval $[0,9]$. If the contrary happens, that is to say, if the total number of green patches is lower than the agent's reference-tree, he increases his minimal-cut by the same amount. The meaning behind is that agents facing a payoff reduction become unsatisfied and are motivated to modify their subjective values and, therefore, their behavior. If the share of the biomass left is lower than the agent's referencetrees (which indicates the share of the forest that should be conserved according to the agent's vision), he attributes the earning reduction to an excessive cutting and will increase his own minimal-cut, becoming more environmentalist, and viceversa. The interplay between slow-changing deep values (reference-tree) and easy-to-change operational procedures (minimal-cut) reflects reality.

At the end of the values update, a selection process among the agents takes place, through the bankruptcy of unsuccessful agents. First, one of the agents with the highest period payoff and one with the lowest payoff in the period are selected. Secondly, a copy of the former (i.e. its referencetrees, while minimal-cut is always equal to zero when a new agent enters the game) replaces the latter. There is a one per cent probability of "mutation", that is to say "copy errors" or new entrants with innovative values. At the end of the selection process all payoffs are put equal to zero and a new period starts.

The results of the open-access version of the model show a complete depletion of the forest and very low payoffs for the agents. Both the number of green patches and the total biomass are reduced 
to a small proportion of the initial quantities. The dynamics of the socio-ecological system shows that a strong decline of the biomass in the very first period leads to a temporary increase of the agents' minimal-cut. However this lasts only for a few periods. Subsequently both payoffs and forest indicators go to zero. This temporary inversion of the depletion trend happens because of the different speed of change of the agents' values. While agents can quickly adapt their minimal-cut to the new situation in every period, changes in reference-trees are driven by the selection process, which involves only one agent per period. At the end of the simulation also the agents' minimal-cut and reference-trees go to zero. This implies that the selection process leads to the prevalence of the agents with higher earnings, which, in turn, are agents believing that the "correct" state of the forest is one with no trees on it. Since we are in an open access situation, with every agent deciding his behaviour only according to his personal values, agents with a low minimal-cut will log always more (Bravo 2011). At the end the typical tragedy of the commons occurs, with depletion of the forest.

\section{Endogenous institution}

In this version of the model one new variable is introduced. At a certain point of the process, agents agree on a shared cutting rule. As explained earlier, an agent is unsatisfied when his current payoff is lower than the one of the previous round. When the number of unsatisfied agents exceeds $2 / 3$ of the population, the mean of the minimal-cut of each agent forms the new variable currentinstitution. This variable indicates the biomass threshold that a patch should contain in order to be logged and this cutting rule becomes compulsory for the whole community. An agent determines his behaviour on the basis of the shared current-institution and not anymore on the basis of his personal minimal-cut. At this point an additional criterion for agent dissatisfaction is in place: the distance between current-institution and minimal-cut. Therefore if an agent faces a payoff reduction or if his personal environmental values are too far from the institutional rule in place, he is unsatisfied. Again, when a high number of unsatisfied agents is reached the institutional rule is updated according to the mean of the agents' new minimal-cut. This new institutional rule will determine agents' behaviour.

The results of this model version show much higher levels of total biomass and of earning of the agents, if compared with the open access situation. These results are in line with the empirical literature (Bravo 2011) and show that an institution endogenous to the community may solve the tragedy of the commons. Observing the dynamics of the model it is possible to understand how these results emerged. Unlike the open access model, the average reference-tree of the agents remains constant until the end of the simulation. The establishment of the management institution diminishes the effect of the selection mechanism, even if this is the same than in the previous version of the model. Like in the previous model version, at the beginning of the simulation there is an increase of the average minimal-cut. However, here this leads to an increase of the shared institution and all the agents will cut less. The endogenously created institution makes the selection mechanism less effective in allowing the survival of more selfish characters among the agents and the defection of the others. The logging decision is no longer matter of personal minimal-cut of the agents, but depends on the system level current-institution. More environmentalist agents (with higher minimal-cut) no longer reach payoffs much lower than the "selfish" ones and therefore they are not excluded from the simulation. This happens because the cutting behaviour does not fluctuate 
anymore following the heterogeneous minimal-cut, therefore the payoffs are more stable as well and the selection mechanism less efficient. This means also that agents with a more "forestfriendly" vision (reference-trees) are not so easily excluded by the simulation (Bravo 2011).

\section{Exogenous institution}

In this version of the model I represent a situation in which an exogenous entity decides on the cutting threshold. Therefore the variable current-institution is not anymore made by the mean of agents' minimal-cut. It is now determined by an external slider controlled by the researcher. Its range goes from zero (which means that a patch should contain at least zero biomass in order to be logged) to [max-tree-growth - 0.5] (which means that a patch should contain at least its maximum biomass level minus 0.5 units in order to be logged). The meaning behind is that, in the first case, an agent is always allowed to cut, and in the latter case an agent is not allowed to cut at all. In this way it is possible to observe both situations of a "strict" cutting rule (with the current-institution slider set to 9) and of a "soft" cutting rule (with the current-institution slider set to 2).

When the cutting rule is set to level 9, it represents a classical situation of "fortress" style protected area, where resource extraction is almost completely forbidden (Hayes 2006, Campbell and VainioMattila 2003). The important difference with reality is that at this stage we still assume that cheating does not exists and that every agent follows the imposed cutting rule. In line with common sense intuitions, the results of this simulation show a good state of the forest, but a very low level of agents payoff. Otherwise, if we shift the cutting level to a "soft" rule (level 2), according to which it is possible to cut a high number of patches, the forest is depleted and the payoffs become even negative, because after a certain number of periods agents do not find any more trees to cut. This outcome is similar to that in the open access scenario.

\section{Cheating}

At this point the possibility of violating the cutting rules is introduced in the model. In both scenarios, with endogenous and with exogenous institution, agents log a patch either if the cutting rule is fulfilled, or if they are unsatisfied. Again, an agent is unsatisfied either if his current payoff is lower than the one of the previous round, or if the cutting rule is too far away from his personal vision.

The only difference between the two settings is that for the endogenous institution version, the current-institution is the mean of the individual minimal-cut, while in the exogenous institution version it is determined by the external slider. Enforcement has not been introduced yet, therefore the impact of the possibility of violating the rule is very strong, regardless of what kind of institution is in place: in both cases the forest is completely logged and the payoffs of the agents are negative. 


\section{Enforcement}

At this stage I introduce settings with rule violation and enforcement, regarding both kinds of institutions, exogenous and endogenous. The enforcement intensity is again determined in both cases by an external slider, since I assume that it depends on the availability of resources of the institution in charge, being endogenous or exogenous to the community, and it is not dependent on the performance of the participatory conservation experience. Additionally, agents now face a random probability to be effectively caught after the violation of the rule, as it is shown in the code.

When the agent enters a patch he logs it if the rule satisfaction condition holds. Otherwise he moves when satisfied, or he logs anyway if he is unsatisfied. If this latter case happens, if the probability to be caught is higher than the enforcement level effectively in place, the agents dies, which means he disappears from the next simulation rounds.

\section{Literature cited}

Bravo, G. 2011. Agents' beliefs and the evolution of institutions for common-pool resource management. Rationality and Society 23(1): 117-152.

Campbell, L. M. and A. Vainio-Mattila. 2003. Participatory development and community-based conservation: opportunities missed for lessons learned? Human Ecology 31: 417-436.

Hayes, T. M. 2006. Parks, people, and forest protection: an institutional assessment of the effectiveness of protected areas. World Development 34(12) : 2064-2075.

Janssen, M. A., R. Goldstone, F. Menczer, and E. Ostrom. 2008. Effect of rule choice in dynamic interactive spatial commons. International Journal of the Commons 2(2): 288-312.

Janssen, M. A., and E. Ostrom E. 2006. Adoption of a new regulation for the governance of common-pool resources by heterogeneous population. Ch. 4. Pages 60-96 in J. M. Baland, P. Bardhan, and S. Bowels, editors. Inequality, cooperation and environmental sustainability. Princeton University Press, Princeton, USA. 
Table A.1. Variables used in the simulation in Netlogo.

\begin{tabular}{|c|c|c|}
\hline $\begin{array}{l}\text { Variables names in } \\
\text { NetLogo }\end{array}$ & Features & Explanation \\
\hline $\begin{array}{l}\text { max-pxcor } \\
\text { "settings") }\end{array}$ & 50 & $\begin{array}{l}\text { Maximum } \mathrm{x} \text { coordinate for patches of the } \mathrm{mxm} \text { toroidal } \\
\text { surface }\end{array}$ \\
\hline $\begin{array}{l}\text { max-pycor } \\
\text { "settings") }\end{array}$ & 50 & $\begin{array}{l}\text { Maximum y coordinate for patches of the mxm toroidal } \\
\text { surface }\end{array}$ \\
\hline \multirow[t]{2}{*}{ trees } & Belongs to $[0$, bmax $]$. & Tree biomass present in a given moment on the patch. \\
\hline & $\begin{array}{l}\text { At the beginning of the simulation it } \\
\text { is randomly distributed in }[1 / 2 \\
\text { bmax, bmax }]\end{array}$ & $\mathrm{x} y$ are the spatial coordinates \\
\hline max-tree-growth & slider & Maximum possible level of biomass per patch \\
\hline \multirow[t]{2}{*}{ pcolor } & $\begin{array}{l}60+5 *(\text { trees } / \text { max-tree-growth })= \\
\text { the more trees the patch has, the } \\
\text { lighter it is. }\end{array}$ & Colour of the patch \\
\hline & & Re-growing probability of an empty patch \\
\hline living-neighbors & & count neighbors with [trees $>0$ ] \\
\hline growth-prob & 0.05 & Basic probability of re-growth in $\mathrm{p}=\mathrm{p}^{*}(\mathrm{~N}+1) /(k+1)$ \\
\hline reference-trees & $\begin{array}{l}\text { At the beginning of each run, it is } \\
\text { drawn randomly from a normal } \\
\text { distribution with mean } 0.5 \text { and } \\
\text { standard deviation } 0.25 \text {. It remains } \\
\text { constant. }\end{array}$ & $\begin{array}{l}\text { Individual belief of each agent: fraction of the initial tree } \\
\text { biomass that should ideally be conserved. }\end{array}$ \\
\hline minimal-cut & $\begin{array}{l}=0 \text { when agents enter the game; it } \\
\text { is updated frequently. }\end{array}$ & $\begin{array}{l}\text { Individual belief of each agent: minimal level of tree biomass } \\
\text { that a patch should have in order to be logged. If it is low, it } \\
\text { means you can cut all. If it is high, it means you can not cut. } \\
\text { Level of cutting that is able to maintain the actual tree } \\
\text { biomass at the desired level. }\end{array}$ \\
\hline \multirow[t]{3}{*}{ payoff } & $\begin{array}{l}=0 \text { at the beginning of each period; } \\
\text { after it depends on agent's actions. }\end{array}$ & Agent's earning when he logs the patch. \\
\hline & & In every round: set payoff payoff - cost \\
\hline & & If he logs: set payoff payoff + [trees] of patch-here \\
\hline old-payoff & & Payoff of the previous round \\
\hline cost & Slider: $[1,10]$ & Fixed cost that the agent pays at every round. \\
\hline $\bar{q}$ & $\begin{array}{l}\text { let q (payoff - old-payoff) / (abs } \\
\text { payoff }+ \text { abs old-payoff) }\end{array}$ & $\begin{array}{l}\text { Probability of changing minimal-cut if the payoff of the } \\
\text { current round is lower than the one of the previous round. }\end{array}$ \\
\hline \multirow{2}{*}{$\begin{array}{l}\text { "Total Biomass" (in } \\
\text { plots) }\end{array}$} & sum [trees] of patches & Total biomass in the initial period (sum of bxy) \\
\hline & & Total biomass in the current period \\
\hline $\begin{array}{l}\text { "Green Patches"(in } \\
\text { plots) }\end{array}$ & count patches with [trees $>0$ ] & \\
\hline
\end{tabular}




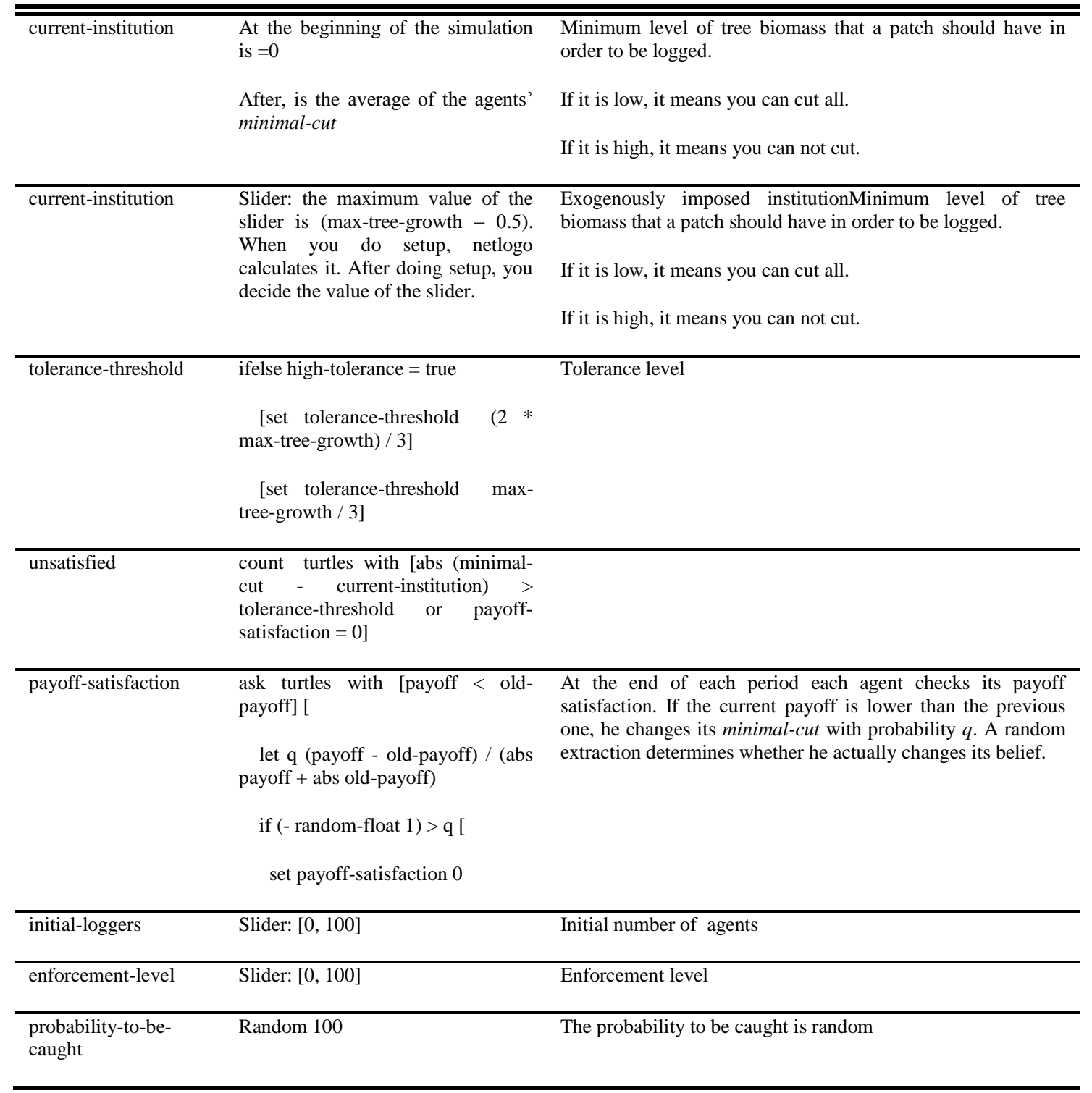

